\title{
IKERLANAK
}

\section{JOAN ROBINSON WAS ALMOST RIGHT: OUTPUT UNDER THIRD- DEGREE PRICE DISCRIMINATION}

$$
\text { by }
$$

Iñaki Aguirre

2009

Working Paper Series: IL. 38/09

Departamento de Fundamentos del Análisis Económico I

Ekonomi Analisiaren Oinarriak I Saila

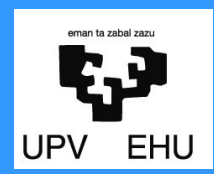

University of the Basque Country 


\title{
Joan Robinson Was Almost Right: Output under Third-Degree Price Discrimination
}

February 2009

\author{
Iñaki Aguirre ${ }^{1}$ \\ University of the Basque Country
}

\begin{abstract}
In this paper, we show that in order for third-degree price discrimination to increase total output, the demands of the strong markets should be, as conjectured by Robinson (1933), more concave than the demands of the weak markets. By making the distinction between adjusted concavity of the inverse demand and adjusted concavity of the direct demand, we are able to state necessary conditions and sufficient conditions for third-degree price discrimination to increase total output.
\end{abstract}

Keywords: Third-Degree Price Discrimination, Output, Monopoly, Welfare.

JEL Classification: D42, L12, L13.

\footnotetext{
${ }^{1}$ I would like to thank Miguel Aramendía, Simon Cowan and Ignacio Palacios-Huerta for helpful comments. Financial support from the Ministerio de Ciencia y Tecnología and FEDER (SEJ2006-05596), and from the Departamento de Educación, Universidades e Investigación del Gobierno Vasco (IT-223-07) is gratefully acknowledged. Departamento de Fundamentos del Análisis Económico I, Avda. Lehendakari Aguirre 83, 48015-Bilbao, Spain. E-mail: inaki.aguirre@ehu.es. Website: www.ehu.es/iaguirre
} 


\section{Introduction}

A move from uniform pricing to third-degree price discrimination generates two effects: first, price discrimination causes a misallocation of goods from high to low value users (in other words, price discrimination is an inefficient way of distributing output between different consumers) and, second, price discrimination affects total output. ${ }^{1}$ Therefore, a necessary condition for third-degree price discrimination to increase social welfare is that it increases total output. ${ }^{2}$ As a result, a focal point has been the analysis of the effects of price discrimination on output. Since Robinson (1933) many articles have addressed this issue, including Leontief (1940), Edwards (1950), Silberberg (1970), Löfgren (1977), Ippolito (1980), Smith and Formby (1981), Formby, Layson and Smith (1983), Schmalensee (1981), Shih, Mai and Liu (1988), Cheung and Wang (1994), Aguirre (2006), Cowan (2007), and Cowan and Vickers (2007), among others. ${ }^{3}$ The effect of third-degree price discrimination on total output is intrinsically related to how the shape of demands in strong markets (markets where the optimal discriminatory price exceeds the optimal single price) compares to that in weak markets (where the optimal discriminatory prices are lower than the single price). It is known from Pigou (1920) that under linear demands price discrimination does not change output. In the general non-linear case, however, the effect of price discrimination on output may be either positive or negative. It is well known (see, for example, Robinson, 1933, Silberberg, 1970, or Schmalensee, 1981) that when all the strong markets have concave demands whereas the weak markets have convex demands (with at least one market with strict concavity or convexity) then third-degree price discrimination increases output. When strong markets have convex demands and weak markets concave demands price discrimination reduces output. In the case in which all the demand

\footnotetext{
${ }^{1}$ See, for example, Ippolito (1980), Schmalensee (1981) or Aguirre (2008) for explicit decompositions of the change in social welfare into these two effects: the misallocation effect and the output effect.

${ }^{2}$ Schmalensee (1981) proves this conjecture assuming nonlinear demand curves, perfectly separated markets and constant marginal cost. Varian (1985), Schwartz (1990) and more recently Bertoletti (2004) generalize the result.

${ }^{3}$ It is assumed throughout the paper that all markets are served under both pricing regimes, uniform pricing and price discrimination. The possibility that price discrimination opens up new markets (and that may even yield Pareto improvements) was also considered by Robinson (1933). See, for example, Battalio and Ekelund (1972), Hausman and MackieMason (1988) and Layson (1994) for more recent analysis.
} 
curves have similar curvature the answer is more complicated. We complete partially the theorem by Robinson (1933) and show that she was almost right when stated that

"If both (curves) are (strictly) concave or both (strictly) convex it is obvious that the result (the effect on output) must depend upon whether or not the more elastic demand curve is, in some sense, "more concave" than the less elastic demand curve (p. 193)." 4

In particular we show that in order for third-degree price discrimination to increase total output the demand in the strong markets should be in some sense more concave than the demand in the weak markets. By making the distinction between adjusted concavity of the inverse demand (the measure used by Robinson, 1933) and adjusted concavity of the direct demand, we are able to state necessary conditions and sufficient conditions for thirddegree price discrimination to increase total output. A sufficient condition for third-degree price discrimination to increase total output is that all curves, demands and inverse demands, are more concave in strong markets. On the other hand, we show that if demands and inverse demands are less (or equally) concave in the strong markets than in the weak markets then thirddegree price discrimination does not increase total output.

The paper is organized as follows. Section 2 introduces different measures of adjusted concavity of demands and inverse demands and shows how they are related to each other. In Section 3, we study the effects of third-degree price discrimination on total output and we state necessary conditions and sufficient conditions for price discrimination to increase output. In Section 4, we arrange previous results in the literature. Finally, Section 5 offers concluding remarks.

\footnotetext{
${ }^{4}$ Robinson (1933) uses the terms concave and convex just in the opposite way to how it will be used in this paper. We follow the modern convention over concavity and convexity.
} 


\section{Direct demands, inverse demands and con- cavity}

Economists typically use the terms demand and inverse demand interchangeably. Although this practice is generally irrelevant, when we study different markets the comparison of their degree of concavity may depend crucially on whether we consider demands or inverse of demands. Assume that the demand function in market $i=1, \ldots, n$ is given by $D_{i}\left(p_{i}\right)$, with $D_{i}^{\prime}\left(p_{i}\right)<0$, where $p_{i}$ is the price charged in that market and the inverse demand function is $p_{i}\left(q_{i}\right)$, with $p_{i}^{\prime}\left(q_{i}\right)<0$, where $q_{i}$ is the quantity sold. We assume that all curves (demands and inverse demands) are everywhere continuous and differentiable. The elasticity of demand of market $i$ is given by $\varepsilon_{i}\left(p_{i}\right)=$ $-D_{i}^{\prime}\left(p_{i}\right) \frac{p_{i}}{D_{i}\left(p_{i}\right)}$ as a function of the price or, equivalently, $\varepsilon_{i}\left(q_{i}\right)=-\frac{1}{p_{i}^{\prime}\left(q_{i}\right)} \frac{p_{i}\left(q_{i}\right)}{q_{i}}$ as a function of the quantity. We distinguish between the concavity of the direct demand and the concavity of the inverse demand. The (adjusted) concavity

of the direct demand in market $i, C_{i}^{D}\left(p_{i}\right)$, is given by $C_{i}^{D}\left(p_{i}\right)=p_{i} \frac{D_{i}^{\prime \prime}\left(p_{i}\right)}{D_{i}^{\prime}\left(p_{i}\right)}$, and the (adjusted) concavity of the inverse demand in market $i, C_{i}^{I}\left(q_{i}\right)$, is given by $C_{i}^{I}\left(q_{i}\right)=q_{i} \frac{p_{i}^{\prime \prime}\left(q_{i}\right)}{p_{i}^{\prime}\left(q_{i}\right)}$. From Robinson $(1933)$ the term $C_{i}^{I}\left(q_{i}\right)$ has been referred to, indistinctly, as adjusted concavity of the demand or adjusted concavity of the inverse demand. However, if we accept that $p_{i}\left(q_{i}\right)$ represents the inverse demand and $D_{i}\left(p_{i}\right)$ the demand function, it seems more reasonable that the concavity of the inverse demand be measured by $C_{i}^{I}($.$) and the concavity of$ the demand by $C_{i}^{D}($.$) . In fact, as we show in the next section, this distinction$ will be important when we study the effects of third-degree price discrimination on output. The next lemma states the relation between these measures of demand concavity.

\section{Lemma 1.}

(i) $C_{i}^{D}\left(p_{i}\right)=\varepsilon_{i}\left(p_{i}\right) C_{i}^{I}\left(p_{i}\right)$.

(ii) $C_{i}^{D}\left(q_{i}\right)=\varepsilon_{i}\left(q_{i}\right) C_{i}^{I}\left(q_{i}\right)$.

Proof. By twice differentiating the identities $p_{i} \equiv p_{i}\left(D_{i}\left(p_{i}\right)\right)$ and $q_{i} \equiv$ $D_{i}\left(p_{i}\left(q_{i}\right)\right)$ with respect to $p_{i}$ and $q_{i}$, respectively, we obtain:

$$
C_{i}^{I}\left(p_{i}\right)=-\frac{D_{i}^{\prime \prime}\left(p_{i}\right) D_{i}\left(p_{i}\right)}{\left[D_{i}^{\prime}\left(p_{i}\right)\right]^{2}}
$$




$$
C_{i}^{D}\left(q_{i}\right)=-\frac{p_{i}^{\prime \prime}\left(q_{i}\right) p_{i}\left(q_{i}\right)}{\left[p_{i}^{\prime}\left(q_{i}\right)\right]^{2}} .
$$

Therefore, taking into account the definition of the elasticity of demand in market $i$, it is direct to obtain $C_{i}^{D}\left(p_{i}\right)=\varepsilon_{i}\left(p_{i}\right) C_{i}^{I}\left(p_{i}\right)$ and $C_{i}^{D}\left(q_{i}\right)=$ $\varepsilon_{i}\left(q_{i}\right) C_{i}^{I}\left(q_{i}\right) .^{5}$

Note that the two measures, $C_{i}^{D}$ and $C_{i}^{I}$, have the same sign: if demand is strictly concave/strictly convex/linear then inverse demand is strictly concave/strictly convex/linear and viceversa. We assume that any demand (or inverse demand) curve which is strictly concave (or linear or strictly convex) remains so throughout the relevant range. On the other hand, we assume that the curves of all the strong (weak) markets have the same general curvature. Put differently, the case where some strong (weak) markets have strictly concave demands and some strong (weak) markets have strictly convex demand is ruled out.

\section{Analysis}

Consider a monopolist selling a good in $n$ perfectly separated markets. The demand function in market $i$ is given by $D_{i}\left(p_{i}\right)$, where $p_{i}$ is the price charged in that market and the inverse demand function is $p_{i}\left(q_{i}\right)$, where $q_{i}$ is the quantity sold. Unit cost, $c$, is assumed constant. We shall obtain the change in total output due to third-degree price discrimination by solving firstly the problem in prices and then the problem in quantities.

Under price discrimination, the optimal policy for the monopolist is given by:

$$
D_{i}\left(p_{i}^{d}\right)+\left(p_{i}^{d}-c\right) D_{i}^{\prime}\left(p_{i}^{d}\right)=0 \quad i=1, \ldots, n,
$$

where $p_{i}^{d}$ denotes the optimal price in market $i$ (and profit functions are assumed strictly concave in the relevant range). The quantity sold in market $i$ is $q_{i}^{d}=D_{i}\left(p_{i}^{d}\right), i=1, \ldots, n$. The total output under price discrimination is

\footnotetext{
${ }^{5}$ See also Cowan (2007) and Cowan and Vickers (2007).
} 
$Q^{d}=\sum_{i=1}^{n} q_{i}^{d}=\sum_{i=1}^{n} D_{i}\left(p_{i}^{d}\right)$. Given first order conditions (1), total output can be expressed as:

$$
Q^{d}=\sum_{i=1}^{n} D_{i}\left(p_{i}^{d}\right)=-\sum_{i=1}^{n}\left(p_{i}^{d}-c\right) D_{i}^{\prime}\left(p_{i}^{d}\right)
$$

Under simple monopoly pricing, profits are maximized by charging all consumers a common price $p^{0}$ such that:

$$
\sum_{i=1}^{n} D_{i}\left(p^{0}\right)+\left(p^{0}-c\right) \sum_{i=1}^{n} D_{i}^{\prime}\left(p^{0}\right)=0
$$

The quantity sold in market $i$ is $q_{i}^{0}=D_{i}\left(p^{0}\right), i=1, \ldots, n$. The total output under uniform pricing is $Q^{0}=\sum_{i=1}^{n} q_{i}^{0}=\sum_{i=1}^{n} D_{i}\left(p^{0}\right)$. Given first order condition (3), total output can be expressed as:

$$
Q^{0}=\sum_{i=1}^{n} D_{i}\left(p^{0}\right)=-\sum_{i=1}^{n}\left(p^{0}-c\right) D_{i}^{\prime}\left(p^{0}\right)
$$

Given conditions (2) and (4) the change in total output, $\Delta Q=Q^{d}-Q^{0}$, is given by:

$$
\Delta Q=Q^{d}-Q^{0}=-\sum_{i=1}^{n}\left(p_{i}^{d}-c\right) D_{i}^{\prime}\left(p_{i}^{d}\right)+\sum_{i=1}^{n}\left(p^{0}-c\right) D_{i}^{\prime}\left(p^{0}\right) .
$$

We can write condition (5) as:

$$
\Delta Q=-\sum_{i=1}^{n}\left\{\int_{p^{0}}^{p_{i}^{d}} d\left[\left(p_{i}-c\right) D_{i}^{\prime}\left(p_{i}\right)\right]\right\}
$$

Therefore, we get: 


$$
\begin{aligned}
\Delta Q & =-\sum_{i=1}^{n}\left\{\int_{p^{0}}^{p_{i}^{d}}\left[D_{i}^{\prime}\left(p_{i}\right)+\left(p_{i}-c\right) D_{i}^{\prime \prime}\left(p_{i}\right)\right] d p_{i}\right\}, \\
& =-\sum_{i=1}^{n}\left\{\Delta q_{i}+\int_{p^{0}}^{p_{i}^{d}}\left(p_{i}-c\right) D_{i}^{\prime \prime}\left(p_{i}\right) d p_{i}\right\}, \\
& =-\frac{1}{2} \sum_{i=1}^{n}\left\{\int_{p^{0}}^{p_{i}^{d}}\left(p_{i}-c\right) D_{i}^{\prime \prime}\left(p_{i}\right) d p_{i}\right\}, \\
& =-\frac{1}{2} \sum_{i=1}^{n}\left\{\int_{p^{0}}^{p_{i}^{d}} L_{i}\left(p_{i}\right) \varepsilon_{i}\left(p_{i}\right) C_{i}^{I}\left(p_{i}\right) D_{i}^{\prime}\left(p_{i}\right) d p_{i}\right\},
\end{aligned}
$$

where $L_{i}\left(p_{i}\right)=\frac{\left(p_{i}-c\right)}{p_{i}}$ is the Lerner index of market $i, \varepsilon_{i}\left(p_{i}\right)=-D_{i}^{\prime}\left(p_{i}\right) \frac{p_{i}}{D_{i}\left(p_{i}\right)}$ is the elasticity of demand of market $i$, and $C_{i}^{I}\left(p_{i}\right)=-\frac{D_{i}^{\prime \prime}\left(p_{i}\right) D_{i}\left(p_{i}\right)}{\left[D_{i}^{\prime}\left(p_{i}\right)\right]^{2}}$ is the adjusted concavity of the inverse demand in market $i$. Given that the adjusted concavity of the direct demand, $C_{i}^{D}\left(p_{i}\right)=p_{i} \frac{D_{i}^{\prime \prime}\left(p_{i}\right)}{D_{i}^{\prime}\left(p_{i}\right)}$, may be written as $C_{i}^{D}\left(p_{i}\right)=\varepsilon_{i}\left(p_{i}\right) C_{i}^{I}\left(p_{i}\right)$, we can express the change in total output as:

$$
\Delta Q=-\frac{1}{2} \sum_{i=1}^{n}\left\{\int_{p^{0}}^{p_{i}^{d}} L_{i}\left(p_{i}\right) C_{i}^{D}\left(p_{i}\right) D_{i}^{\prime}\left(p_{i}\right) d p_{i}\right\} .
$$

On the other hand, under price discrimination, the optimal policy for the monopolist consists in fixing an output for market $i$ such that:

$$
p_{i}\left(q_{i}^{d}\right)-c+q_{i}^{d} p_{i}^{\prime}\left(q_{i}^{d}\right)=0 \quad i=1, \ldots, n,
$$

where $q_{i}^{d}$ denotes the optimal output in market $i$ (and profit functions are assumed strictly concave in the relevant range). The total output under price discrimination is $Q^{d}=\sum_{i=1}^{n} q_{i}^{d}$ and, given first order conditions (9), can be expressed as:

$$
Q^{d}=\sum_{i=1}^{n} q_{i}^{d}=-\sum_{i=1}^{n}\left[p_{i}\left(q_{i}^{d}\right)-c\right] \frac{1}{p_{i}^{\prime}\left(q_{i}^{d}\right)} .
$$

Under simple monopoly pricing, profits are maximized by charging all consumers a common price $p^{0}$. The total output under uniform pricing, $Q^{0}=\sum_{i=1}^{n} q_{i}^{0}$, can be expressed as: 


$$
Q^{0}=\sum_{i=1}^{n} q_{i}^{0}=-\sum_{i=1}^{n}\left[p_{i}\left(q_{i}^{0}\right)-c\right] \frac{1}{p_{i}^{\prime}\left(q_{i}^{0}\right)} .
$$

We follow closely the analysis by Cheung and Wang (1994). Given conditions (10) and (11), the change in total output is given by:

$$
\Delta Q=Q^{d}-Q^{0}=-\sum_{i=1}^{n}\left[p_{i}\left(q_{i}^{d}\right)-c\right] \frac{1}{p_{i}^{\prime}\left(q_{i}^{d}\right)}+\sum_{i=1}^{n}\left[p_{i}\left(q_{i}^{0}\right)-c\right] \frac{1}{p_{i}^{\prime}\left(q_{i}^{0}\right)} .
$$

We can rewrite (12) as:

$$
\Delta Q=-\sum_{i=1}^{n}\left\{\int_{q_{i}^{0}}^{q_{i}^{d}} d\left[\left[p_{i}\left(q_{i}\right)-c\right] \frac{1}{p_{i}^{\prime}\left(q_{i}\right)}\right]\right\} .
$$

Therefore, the change in total output can be expressed as:

$$
\begin{aligned}
\Delta Q & =-\sum_{i=1}^{n}\left\{\int_{q_{i}^{0}}^{q_{i}^{d}}\left\{\left[p_{i}^{\prime}\left(q_{i}\right)\right]^{2}-\left[p_{i}\left(q_{i}\right)-c\right] p_{i}^{\prime \prime}\left(q_{i}\right)\right\} \frac{1}{\left[p_{i}^{\prime}\left(q_{i}\right)\right]^{2}} d q_{i}\right\}, \\
& =-\sum_{i=1}^{n}\left\{\int_{q_{i}^{0}}^{q_{i}^{d}}\left\{1-\left[p_{i}\left(q_{i}\right)-c\right] \frac{p_{i}^{\prime \prime}\left(q_{i}\right)}{\left[p_{i}^{\prime}\left(q_{i}\right)\right]^{2}}\right\} d q_{i}\right\}, \\
& =\sum_{i=1}^{n}-\Delta q_{i}+\sum_{i=1}^{n}\left\{\int_{q_{i}^{0}}^{q_{i}^{d}}\left[p_{i}\left(q_{i}\right)-c\right] \frac{p_{i}^{\prime \prime}\left(q_{i}\right)}{\left[p_{i}^{\prime}\left(q_{i}\right)\right]^{2}} d q_{i}\right\}, \\
& =\frac{1}{2} \sum_{i=1}^{n}\left\{\int_{q_{i}^{0}}^{q_{i}^{d}}\left[p_{i}\left(q_{i}\right)-c\right] \frac{p_{i}^{\prime \prime}\left(q_{i}\right)}{\left[p_{i}^{\prime}\left(q_{i}\right)\right]^{2}} d q_{i}\right\}, \\
& =\frac{1}{2} \sum_{i=1}^{n}\left\{\int_{q_{i}^{0}}^{q_{i}^{d}} \frac{\left[p_{i}\left(q_{i}\right)-c\right]}{p_{i}\left(q_{i}\right)} \frac{p_{i}\left(q_{i}\right) q_{i}}{q_{i}} \frac{p_{i}^{\prime \prime}\left(q_{i}\right)}{\left[p_{i}^{\prime}\left(q_{i}\right)\right]^{2}} d q_{i}\right\}, \\
& =-\frac{1}{2} \sum_{i=1}^{n}\left\{\int_{q_{i}^{0}}^{q_{i}^{d}} L_{i}\left(q_{i}\right) \varepsilon_{i}\left(q_{i}\right) C_{i}^{I}\left(q_{i}\right) d q_{i}\right\},
\end{aligned}
$$

where $L_{i}\left(q_{i}\right)=\frac{\left[p_{i}\left(q_{i}\right)-c\right]}{p_{i}\left(q_{i}\right)}$ is the Lerner index of market $i, \varepsilon_{i}\left(q_{i}\right)=-\frac{1}{p_{i}^{\prime}\left(q_{i}\right)} \frac{p_{i}\left(q_{i}\right)}{q_{i}}$ is the elasticity of demand of market $i$, and $C_{i}^{I}\left(q_{i}\right)=q_{i} \frac{p_{i}^{\prime \prime}\left(q_{i}\right)}{p_{i}^{\prime}\left(q_{i}\right)}$ is the adjusted concavity of the inverse demand in market $i$. Given that the adjusted concavity 
of the direct demand, $C_{i}^{D}\left(q_{i}\right)=-\frac{p_{i}^{\prime \prime}\left(q_{i}\right) p_{i}\left(q_{i}\right)}{\left[p_{i}^{\prime}\left(q_{i}\right)\right]^{2}}$, is given by $C_{i}^{D}\left(q_{i}\right)=\varepsilon_{i}\left(q_{i}\right) C_{i}^{I}\left(q_{i}\right)$, we can express the change in total output as:

$$
\Delta Q=-\frac{1}{2} \sum_{i=1}^{n}\left\{\int_{q_{i}^{0}}^{q_{i}^{d}} L_{i}\left(q_{i}\right) C_{i}^{D}\left(q_{i}\right) d q_{i}\right\} .
$$

Although we conjecture that the results are more general, following Cheung and Wang (1994) we restrict our analysis to say that demands in strong markets are more (less) concave than demands in weak markets if the minimum (maximum) value of demand adjusted concavity over the range of output levels between the simple monopoly and discriminatory outputs in each of the strong markets is greater (lower) than the maximum (minimum) value of demand adjusted concavity over the corresponding ranges of output in all of the weak markets. In a similar way, we may define when the inverse demands are more or less concave in strong markets as compared to weak markets. We define these maximum and minimum values of adjusted concavity as:

$$
\begin{aligned}
& \bar{C}_{s}^{D}=\max \left\{C_{i}^{D}\left(q_{i}\right) ; q_{i} \in\left[q_{i}^{d}, q_{i}^{0}\right], i \in S\right\}=\max \left\{C_{i}^{D}\left(p_{i}\right) ; p_{i} \in\left[p^{0}, p_{i}^{d}\right], i \in S\right\}, \\
& \bar{C}_{w}^{D}=\max \left\{C_{i}^{D}\left(q_{i}\right) ; q_{i} \in\left[q_{i}^{0}, q_{i}^{d}\right], i \in W\right\}=\max \left\{C_{i}^{D}\left(p_{i}\right) ; p_{i} \in\left[p_{i}^{d}, p^{0}\right], i \in W\right\}, \\
& \underline{C}_{s}^{D}=\min \left\{C_{i}^{D}\left(q_{i}\right) ; q_{i} \in\left[q_{i}^{d}, q_{i}^{0}\right], i \in S\right\}=\min \left\{C_{i}^{D}\left(p_{i}\right) ; p_{i} \in\left[p^{0}, p_{i}^{d}\right], i \in S\right\}, \\
& \underline{C}_{w}^{D}=\min \left\{C_{i}^{D}\left(q_{i}\right) ; q_{i} \in\left[q_{i}^{0}, q_{i}^{d}\right], i \in W\right\}=\min \left\{C_{i}^{D}\left(p_{i}\right) ; p_{i} \in\left[p_{i}^{d}, p^{0}\right], i \in W\right\}, \\
& \bar{C}_{s}^{I}=\max \left\{C_{i}^{I}\left(q_{i}\right) ; q_{i} \in\left[q_{i}^{d}, q_{i}^{0}\right], i \in S\right\}=\max \left\{C_{i}^{I}\left(p_{i}\right) ; p_{i} \in\left[p^{0}, p_{i}^{d}\right], i \in S\right\}, \\
& \bar{C}_{w}^{I}=\max \left\{C_{i}^{I}\left(q_{i}\right) ; q_{i} \in\left[q_{i}^{0}, q_{i}^{d}\right], i \in W\right\}=\max \left\{C_{i}^{I}\left(p_{i}\right) ; p_{i} \in\left[p_{i}^{d}, p^{0}\right], i \in W\right\}
\end{aligned}
$$




$$
\begin{gathered}
\underline{C}_{s}^{I}=\min \left\{C_{i}^{I}\left(q_{i}\right) ; q_{i} \in\left[q_{i}^{d}, q_{i}^{0}\right], i \in S\right\}=\min \left\{C_{i}^{I}\left(p_{i}\right) ; p_{i} \in\left[p^{0}, p_{i}^{d}\right], i \in S\right\}, \\
\underline{C}_{w}^{I}=\min \left\{C_{i}^{I}\left(q_{i}\right) ; q_{i} \in\left[q_{i}^{0}, q_{i}^{d}\right], i \in W\right\}=\min \left\{C_{i}^{I}\left(p_{i}\right) ; p_{i} \in\left[p_{i}^{d}, p^{0}\right], i \in W\right\},
\end{gathered}
$$

where $S$ denotes the set of strong markets which collects the markets where the optimal discriminatory price exceeds the optimal single price, $S=\left\{i / p_{i}^{d}>\right.$ $\left.p^{0}\right\}$, and $W$ denotes the set of weak markets which collects the markets where the optimal discriminatory price are lower than the single price, $W=\left\{i / p_{i}^{d}<\right.$ $\left.p^{0}\right\}$. Therefore, when $\underline{C}_{s}^{D}>\bar{C}_{w}^{D}$ then the demands in strong markets are more concave than the demands in weak markets. When $\bar{C}_{s}^{D}<\underline{C}_{w}^{D}$ then the demands in strong markets are less concave than the demands in weak markets. Note that the demands in strong markets are equally concave than the demands in weak markets when $\underline{C}_{s}^{D}=\bar{C}_{w}^{D}=\bar{C}_{s}^{D}=\underline{C}_{w}^{D}$. In a similar way, when $\underline{C}_{s}^{I}>\bar{C}_{w}^{I}\left(\bar{C}_{s}^{I}<\underline{C}_{w}^{I}\right)$ then the inverse demands are more (less) concave in strong markets than in weak markets while when $\underline{C}_{s}^{I}=\bar{C}_{w}^{I}=\bar{C}_{s}^{I}=\underline{C}_{w}^{I}$ then all inverse demands are equally concave.

The following theorem partially completes the analysis of the effects of third-degree price discrimination on total output seventy five years after the pioneering work by Robinson (1933).

Theorem 1. Effects of third-degree price discrimination on total output

(i) If both direct demand curves and inverse demand curves are more concave in strong markets than in weak markets, then third-degree price discrimination increases total output.

(ii) If both direct demand curves and inverse demand curves are less (or equally) concave in strong markets than in weak markets, then third-degree price discrimination does not increase total output.

Proof. We start with part (ii). We have assumed that any demand curve which is strictly concave (or linear or strictly convex) remains so throughout the relevant range. We now show that total output does not increase in the cases in which both direct demand and inverse demand curves are less (or equally) concave in strong markets than in weak markets:

a) If demands and inverse demands are all linear, it is straightforward from (7) or (8), and from (14) or (15), that output remains unchanged, $\Delta Q=0$. 
b) If demand curves are convex (strictly convex) in all strong markets and strictly concave (concave) in all weak markets, then it is straightforward from (7) and (8), or from (14) and (15), than output decreases, $\Delta Q<0$.

c) All demands are strictly concave. We follow the analysis by Cheung and Wang (1994). It is easy to check by following a profit maximization argument that $L_{i}\left(q_{i}\right) \varepsilon_{i}\left(q_{i}\right)>1$ if $i \in W$ and $q_{i} \in\left[q_{i}^{0}, q_{i}^{d}\right)$, and $L_{i}\left(q_{i}\right) \varepsilon_{i}\left(q_{i}\right)<1$ if $i \in S$ and $q_{i} \in\left(q_{i}^{d}, q_{i}^{0}\right]$. Given that all curves are strictly concave condition (14) implies:

$$
\Delta Q<-\frac{1}{2} \sum_{i=1}^{n}\left\{\int_{q_{i}^{0}}^{q_{i}^{d}} C_{i}^{I}\left(q_{i}\right) d q_{i}\right\} .
$$

If the minimum value of the inverse demand adjusted concavity in each of the weak markets, $\underline{C}_{w}^{I}$, is greater than or equal to the maximum value of the inverse demand adjusted concavity in all of the strong markets, $\bar{C}_{s}^{I}$, then:

$$
\Delta Q<-\frac{1}{2} \sum_{i=1}^{n}\left\{\int_{q_{i}^{0}}^{q_{i}^{d}} C_{i}^{I}\left(q_{i}\right) d q_{i}\right\} \leq-\frac{1}{2} \bar{C}_{s}^{I} \sum_{i=1}^{n}\left\{\int_{q_{i}^{0}}^{q_{i}^{d}} d q_{i}\right\}=-\frac{1}{2} \bar{C}_{s}^{I} \Delta Q .
$$

Therefore, $\Delta Q<0$ (notice that $\bar{C}_{s}^{I}>0$ ). Given that the elasticity of demand is greater in weak markets than in strong markets, then the minimum value of the demand adjusted concavity in each of the weak markets, $\underline{C}_{w}^{D}$, is greater than or equal to the maximum value of the demand adjusted concavity in all of the strong markets, $\bar{C}_{s}^{D}$.

d) All demands are strictly convex. Condition (15) may be written as:

$$
\Delta Q=\frac{1}{2} \sum_{i=1}^{n}\left\{\int_{q_{i}^{0}}^{q_{i}^{d}} L_{i}\left(q_{i}\right)\left[-C_{i}^{D}\left(q_{i}\right)\right] d q_{i}\right\} .
$$

If the minimum value of the demand adjusted concavity in each of the weak markets, $\underline{C}_{w}^{D}$, is greater than or equal to the maximum value of the demand adjusted concavity in all of the strong markets, $\bar{C}_{s}^{D}$, then:

$$
\Delta Q=\frac{1}{2} \sum_{i=1}^{n}\left\{\int_{q_{i}^{0}}^{q_{i}^{d}} L_{i}\left(q_{i}\right)\left[-C_{i}^{D}\left(q_{i}\right)\right] d q_{i}\right\}<\frac{1}{2} \sum_{i=1}^{n}\left\{\int_{q_{i}^{0}}^{q_{i}^{d}} L_{i}\left(q_{i}\right)\left[-\bar{C}_{s}^{D}\right] d q_{i}\right\} .
$$


On the other hand, given that $L_{i}\left(q_{i}\right)$ is decreasing in $q_{i}, \int_{q_{i}^{0}}^{q_{i}^{d}} L_{i}\left(q_{i}\right) d q_{i}<$ $\int_{q_{i}^{0}}^{q_{i}^{d}} L_{i}\left(q_{i}^{0}\right) d q_{i}$ where $L_{i}\left(q_{i}^{0}\right)=\frac{p^{0}-c}{p^{0}}$ (see Cheung and Wang, 1994). Therefore, we obtain:

$$
\begin{aligned}
\Delta Q & <\frac{1}{2} \sum_{i=1}^{n}\left\{\int_{q_{i}^{0}}^{q_{i}^{d}} L_{i}\left(q_{i}\right)\left[-\bar{C}_{s}^{D}\right] d q_{i}\right\}=\frac{1}{2} \sum_{i=1}^{n} L_{i}\left(q_{i}^{0}\right)\left[-\bar{C}_{s}^{D}\right]\left\{\int_{q_{i}^{0}}^{q_{i}^{d}} d q_{i}\right\} \\
& =\frac{1}{2}\left[-\bar{C}_{s}^{D}\right] \frac{p^{0}-c}{p^{0}} \Delta Q .
\end{aligned}
$$

Therefore, $\Delta Q<0$ (notice that, from second order conditions, $\left[-\bar{C}_{s}^{D}\right] \frac{p^{0}-c}{p^{0}}<$ $2)$. Note also that given that the elasticity of demand is greater in weak markets than in strong markets, when $0>\underline{C}_{w}^{D}>\bar{C}_{s}^{D}$ then the minimum value of the inverse demand adjusted concavity in each of the weak markets, $\underline{C}_{w}^{I}$, is greater than or equal to the maximum value of the inverse demand adjusted concavity in all of the strong markets, $\bar{C}_{s}^{I}$.

We next show that $\Delta Q>0$ in all cases where direct demand and inverse demand curves are more concave in strong than in weak markets, that is part (i):

e) If demand curves are concave (strictly concave) in all strong markets and strictly convex (convex) in all weak markets, then it is straightforward from (7) and (8), or from (14) and (15), than output increases, $\Delta Q>0$.

f) All demands are strictly concave. If the minimum value of the demand adjusted concavity in each of the strong markets, $\underline{C}_{s}^{D}$, is greater than or equal to the maximum value of the demand adjusted concavity in all of the weak markets, $\bar{C}_{w}^{D}$, then, from condition (15), we have:

$$
\Delta Q=-\frac{1}{2} \sum_{i=1}^{n}\left\{\int_{q_{i}^{0}}^{q_{i}^{d}} L_{i}\left(q_{i}\right) C_{i}^{D}\left(q_{i}\right) d q_{i}\right\}>-\frac{1}{2} \sum_{i=1}^{n} \underline{C}_{w}^{D}\left\{\int_{q_{i}^{0}}^{q_{i}^{d}} L_{i}\left(q_{i}\right) d q_{i}\right\} .
$$

On the other hand, given that $L_{i}\left(q_{i}\right)$ is decreasing in $q_{i},-\int_{q_{i}^{0}}^{q_{i}^{d}} L_{i}\left(q_{i}\right) d q_{i}>$ $-\int_{q_{i}^{0}}^{q_{i}^{d}} L_{i}\left(q_{i}^{0}\right) d q_{i}$ where $L_{i}\left(q_{i}^{0}\right)=\frac{p^{0}-c}{p^{0}}$ (see Cheung and Wang, 1994). Therefore, we obtain: 


$$
\Delta Q>-\frac{1}{2} \sum_{i=1}^{n} \underline{C}_{w}^{D} L_{i}\left(q_{i}^{0}\right)\left\{\int_{q_{i}^{0}}^{q_{i}^{d}} d q_{i}\right\}=-\frac{1}{2} \underline{C}_{w}^{D} \frac{p^{0}-c}{p^{0}} \Delta Q .
$$

Therefore, $\Delta Q>0$. Note that given that the elasticity of demand is greater in weak markets than in strong markets, when $\underline{C}_{s}^{D}>\bar{C}_{w}^{D}>0$ then the minimum value of the inverse demand adjusted concavity in each of the strong markets, $\underline{C}_{s}^{I}$, is greater than or equal to the maximum value of the inverse demand adjusted concavity in all of the weak markets, $\bar{C}_{w}^{I}$.

g) All demands are strictly convex. The proof in this case is based on Cheung and Wang (1994). Given that all curves are strictly convex and that $L_{i}\left(q_{i}\right) \varepsilon_{i}\left(q_{i}\right)>1$ if $i \in W$ and $q_{i} \in\left[q_{i}^{0}, q_{i}^{d}\right)$, and $L_{i}\left(q_{i}\right) \varepsilon_{i}\left(q_{i}\right)<1$ if $i \in S$ and $q_{i} \in\left(q_{i}^{d}, q_{i}^{0}\right]$ then condition (14) implies:

$$
\Delta Q>-\frac{1}{2} \sum_{i=1}^{n}\left\{\int_{q_{i}^{0}}^{q_{i}^{d}} C_{i}^{I}\left(q_{i}\right) d q_{i}\right\} .
$$

If the minimum value of the inverse demand adjusted concavity in each of the strong markets, $\underline{C}_{s}^{I}$, is greater than or equal to the maximum value of the inverse demand adjusted concavity in all of the weak markets, $\bar{C}_{w}^{I}$, then we have:

$$
\Delta Q>-\frac{1}{2} \sum_{i=1}^{n}\left\{\int_{q_{i}^{0}}^{q_{i}^{d}} C_{i}^{I}\left(q_{i}\right) d q_{i}\right\}>-\frac{1}{2} \underline{C}_{s}^{I} \sum_{i=1}^{n}\left\{\int_{q_{i}^{0}}^{q_{i}^{d}} d q_{i}\right\}=-\frac{1}{2} C_{s}^{I} \Delta Q
$$

From second order conditions, $0>\underline{C}_{s}^{I} \geqslant-2$ and therefore $\Delta Q>0$. Given that the elasticity of demand is greater in weak markets than in strong markets, then the minimum value of the demand adjusted concavity in each of the strong markets, $\underline{C}_{s}^{D}$, is greater than or equal to the maximum value of the demand adjusted concavity in all of the weak markets, $\bar{C}_{w}^{D}$.

Note that Theorem 1 a sufficient condition for third-degree price discrimination to increase total output: if both types of curves, demands and inverse demands, are more concave in the strong markets then price discrimination increases total output. When both types of curves are less (or equally) concave in strong markets than in weak markets then price discrimination reduces (maintains constant) total output. Given Theorem 1 we may conjecture that a necessary condition for third-degree price discrimination to 
increase total output is that at least one family of curves, direct or inverse demands, are more concave in strong markets than in weak markets. However, given our concavity comparison criterion we only state that a necessary condition for price discrimination to increase total output is that both types of curves cannot be less concave in strong markets than in weak markets. The next corollary states necessary conditions and sufficient conditions when all demand curves are strictly concave or strictly convex.

\section{Corollary 1.}

(i) When all markets have strictly concave demands a sufficient (necessary) condition for third-degree price discrimination to increase total output is that the demands (inverse demands) of the strong markets are more (not less) concave than the demands (inverse demands) of the weak markets.

(ii) When all markets have strictly convex demands a necessary (sufficient) condition for third-degree price discrimination to increase total output is that the demands (inverse demands) of the strong markets are not less (more) concave than the demands (inverse demands) of the weak markets.

\section{Proof.}

(i) If the demands of the strong markets are more concave than the demands of the weak markets, $\underline{C}_{s}^{D}>\bar{C}_{w}^{D}>0$, then:

$$
\underline{C}_{s}^{I} \geq \frac{C_{s}^{D}}{\underline{\varepsilon}_{s}}>\frac{\bar{C}_{w}^{D}}{\bar{\varepsilon}_{w}} \geq \bar{C}_{w}^{I},
$$

given that by definition strong markets have lower elasticities than weak markets. Therefore, both demands and inverse demands are more concave in strong markets than in weak markets and Theorem 1 implies that a sufficient condition for third-degree price discrimination to increase total output is satisfied.

(ii) Assume, on the contrary, that $\bar{C}_{s}^{D}<\underline{C}_{w}^{D}<0$. Then:

$$
\bar{C}_{s}^{I}=\frac{\bar{C}_{s}^{D}}{\bar{\varepsilon}_{s}}<\frac{C_{w}^{D}}{\underline{\varepsilon}_{w}}=\underline{C}_{w}^{I}<0,
$$

and, therefore, Theorem 1 implies that price discrimination reduces output. 


\section{Related literature}

According to the above analysis we can arrange previous results in the literature as follows:

\section{a) Linear demands}

When direct demands and, therefore, inverse demands are all linear, it is well known at least from Pigou (1920) that total output is the same under both pricing regimes, price discrimination and uniform pricing (of course, when all markets are served under both pricing policies). Note that we might apply the second part in the theorem to obtain the result: under linear demands the sufficient condition for third-degree price discrimination not to increase output is satisfied.

b) Strong markets with strictly concave (concave) demands and weak markets with convex (strictly convex) demands

In this case, third-degree price discrimination increases output (see, for example, Robinson, 1933, Edwards, 1950, Silberberg, 1970, Schmalensee, 1981, Shih et al., 1988, among others, or more recently Cowan and Vickers, 2007). Note that in this case the sufficient condition for third-degree price discrimination to increase total output is satisfied: both direct demands and inverse demands are more concave in strong markets than in weak markets.

c) Strong markets with strictly convex (convex) demands and weak markets with concave (strictly concave) demands

Third-degree price discrimination decreases output (see, for example, Robinson, 1933, Edwards , 1950, Silberberg, 1970, Schmalensee, 1981, Shih et al., 1988, or Cowan and Vickers, 2007) because, from Theorem 1, when direct demands and inverse demands are less concave in strong markets than in weak markets then output decreases.

Note that in the three above cases the comparison of concavity (the ranking) between strong and weak markets is similar when we use direct demands or inverse demands. Direct demands and inverse demands are equally concave in strong and weak markets in case a), more concave in strong markets than in weak markets for the case b) and more concave in weak markets than in strong markets for the case c). However, when all demand curves (and inverse demand curves) are strictly concave or strictly convex, it is possible that the demand curves are more concave in the strong markets while the inverse demand curves are more concave in weak markets and viceversa. 


\section{d) Constant elasticity demands}

One of the more popular demand families, constant elasticity demands, has proven particularly resistant to analysis in that neither the "adjusted concavity" criterion (Robinson,1933, Cheung and Wang, 1994) nor the "slope ratio" criterion (Edwards, 1950), nor the "mean-value theorem" criterion (Shih et al., 1988), among others, serve to explain the direction of the output effect. However, it is now well known that price discrimination increases output under this kind of demands.

Greenhut and Ohta (1976) show through a numerical example that price discrimination may increase output with constant elasticity demands. Their note constitutes a counterexample to the "adjusted concavity criterion" as proposed by Robinson (1933) which would state that price discrimination reduces output under constant elasticity demands given that inverse demands are more concave in weak markets. Recently, Cheung and Wang (1994) reformulate this criterion and show how it is not applicable to this type of market demands.

Ippolito (1980), in an excellent but rarely cited paper, uses simulations and obtains the result that total output increases under third-degree price discrimination in the two-market case. Formby et al. (1983) using Lagrangean techniques show that monopolistic price discrimination increases total output over a wide range of constant elasticities. Recently, Aguirre (2006) provides a more general and simpler proof by using the Bernoulli inequality. Finally, Cowan and Vickers (2007) propose an easier and more intuitive proof.

Is it possible by using Theorem 1 to explain what is happening with constant elasticity demands? We next check how with constant elasticity demands the necessary condition is satisfied but not the sufficient condition for third-degree price discrimination to increase total output. Assume that the demand function in market $i$ is given by $D_{i}\left(p_{i}\right)=a_{i} p_{i}^{-\varepsilon_{i}}$, where $a_{i}$ is a positive parameter and $\varepsilon_{i}>1$ is the elasticity of demand. It is easy to check that the index of concavity of the demand, $C_{i}^{D}(p)$, and the index of concavity of the inverse of demand, $C_{i}^{I}(p)$, are, respectively, given by:

$$
\begin{gathered}
C_{i}^{D}(p)=p \frac{D_{i}^{\prime \prime}(p)}{D_{i}^{\prime}(p)}=-\left(1+\varepsilon_{i}\right), \\
C_{i}^{I}(p)=\frac{C_{i}^{D}(p)}{\varepsilon_{i}(p)}=-\left(\frac{1+\varepsilon_{i}}{\varepsilon_{i}}\right) .
\end{gathered}
$$

Given two arbitrary markets $i$ and $j$, if $\varepsilon_{i}>\varepsilon_{j}$ then it is satisfied that 
$C_{i}^{D}(p)<C_{j}^{D}(p)$ and $C_{i}^{I}(p)>C_{j}^{I}(p)$. Therefore, when the criterion of concavity uses inverse demands the ranking of markets is just the opposite to that when the criterion uses direct demands. In other words, the demand of strong markets is more concave than the demand of the weak markets and the inverse of demand of strong markets is less concave than the inverse of demand of weak markets: note that $\underline{C}_{s}^{D}>\bar{C}_{w}^{D}$ and $\bar{C}_{s}^{I}<\underline{C}_{w}^{I}$. That is, according to Theorem 1, the necessary condition is satisfied but not the sufficient condition for third-degree price discrimination to increase output.

e) Constant adjusted concavity demand curves

Shih et al. (1988) propose the following class of constant adjusted concavity (inverse) demand curves: $p_{i}=a_{i}-b_{i} q_{i}^{A+1}\left(i=1, \ldots, n, a_{i}, b_{i}>0\right.$, $A>-1)$, where $C_{i}^{I}\left(q_{i}\right)=q_{i} \frac{p_{i}^{\prime \prime}\left(q_{i}\right)}{p_{i}^{\prime}\left(q_{i}\right)}=A$ is Robinson's adjusted concavity. Shih et al. (1988) show that when $A>0$ (that is, strictly concave inverse demands) price discrimination reduces output and when $-1<A<0$ (that is, strictly convex inverse demands) price discrimination increases output. Note that the elasticity of demand and the index of concavity of the direct demand are, respectively:

$$
\begin{gathered}
\varepsilon_{i}\left(q_{i}\right)=\frac{1}{A+1} \frac{a_{i}-b_{i} q_{i}^{A+1}}{b_{i} q_{i}^{A+1}}, \\
C_{i}^{D}\left(q_{i}\right)=C_{i}^{I}\left(q_{i}\right) \varepsilon_{i}\left(q_{i}\right)=\frac{A}{A+1} \frac{a_{i}-b_{i} q_{i}^{A+1}}{b_{i} q_{i}^{A+1}} .
\end{gathered}
$$

or as a function of prices:

$$
\begin{gathered}
\varepsilon_{i}\left(p_{i}\right)=\frac{1}{A+1} \frac{p_{i}}{a_{i}-p_{i}} \\
C_{i}^{D}\left(p_{i}\right)=C_{i}^{I}\left(p_{i}\right) \varepsilon_{i}\left(p_{i}\right)=\frac{A}{A+1} \frac{p_{i}}{a_{i}-p_{i}} .
\end{gathered}
$$

Given two arbitrary markets $i$ and $j$, if $\varepsilon_{i}(p)>\varepsilon_{j}(p)$ then $C_{i}^{D}(p)>(<$ $C_{j}^{D}(p)$ and $C_{i}^{I}(p)=C_{j}^{I}(p)$ when demands are strictly concave (convex), $A>(<) 0$. Note that when $A>0$ then $\bar{C}_{s}^{D}<\underline{C}_{w}^{D}$ and $\bar{C}_{s}^{I}=\underline{C}_{w}^{I}$, whereas if $A<0$ then $\underline{C}_{s}^{D}>\bar{C}_{w}^{D}$ and $\bar{C}_{s}^{I}=\underline{C}_{w}^{I}$. Therefore, Theorem 1 implies that 
output decreases when demands are strictly concave and output increases when demands are strictly convex.

f) Affine transformations and strictly concave transformations of demand Cowan (2007) analyzes the welfare effects of third-degree price discrimination when demand in one market is a shifted version of demand in the other market. In particular, assume that there are only two markets and the demand in the strong market is an affine transformation of the demand in the weak market: $D_{s}(p)=\alpha+\beta D_{w}(p)$ with $\alpha \geq 0$ and $\beta>0$. It is straightforward to check that the adjusted concavities are given by:

$$
\begin{gathered}
C_{s}^{D}(p)=C_{w}^{D}(p) \\
C_{s}^{I}(p)=C_{w}^{I}(p)-\frac{\alpha D_{w}^{\prime \prime}(p)}{\beta\left[D_{w}^{\prime}(p)\right]^{2}} .
\end{gathered}
$$

It is easy to find examples with strictly convex demands where $\bar{C}_{s}^{D} \leq \underline{C}_{w}^{D}$ and $\bar{C}_{s}^{I}<\underline{C}_{w}^{I}$ and, therefore, from Theorem 1, output decreases. For example, Cowan (2007) obtains the result that when the underlying demand function, $D_{w}(p)$, is iso-elastic output decreases.

On the other hand, when the demand of the strong market is a strictly concave transformation of the demand of the weak market, $D_{s}(p)=\Psi\left(D_{w}(p)\right)$, $\Psi^{\prime}>0$ and $\Psi^{\prime \prime}<0$, it is easy to find examples where output increases. For example, under iso-elastic demands the demand of the strong market may be written as a concave transformation of the demand of the weak market: $D_{s}(p)=\Psi\left(D_{w}(p)\right)=k\left(D_{w}(p)\right)^{\frac{\varepsilon_{s}}{\varepsilon_{w}}}$, where $k=a_{s}\left(a_{w}\right)^{-\frac{\varepsilon_{s}}{\varepsilon_{w}}}>0, \Psi^{\prime}>0$ and $\Psi^{\prime \prime}<0$, and we know that with constant elasticity demands output increases.

Note that in the case of two markets if both the demand and the inverse demand in the strong market were strictly concave transformations, respectively, of the demand and the inverse demand in the weak market then the sufficient condition (from Theorem 1) for third-degree price discrimination to increase output would be satisfied.

g) Constant inverse demand curvature

Cowan and Vickers (2007) propose the following class of constant adjusted concavity (inverse) demand curves: : $p_{i}=a_{i}-\frac{b_{i}}{1+A_{i}} q_{i}^{1+A_{i}}\left(a_{i}, b_{i}>0, A_{i} \neq\right.$ 
$-1)$. Note that the elasticity of demand and the index of concavity of the direct demand are, respectively:

$$
\begin{gathered}
\varepsilon_{i}\left(p_{i}\right)=\frac{1}{A_{i}+1} \frac{p_{i}}{a_{i}-p_{i}}, \\
C_{i}^{I}\left(p_{i}\right)=A_{i}, \\
C_{i}^{D}\left(p_{i}\right)=C_{i}^{I}\left(p_{i}\right) \varepsilon_{i}\left(p_{i}\right)=\frac{A_{i}}{A_{i}+1} \frac{p_{i}}{a_{i}-p_{i}} .
\end{gathered}
$$

Note that this family of demands perfectly illustrates Theorem 1 .

When demands are strictly concave, given two arbitrary markets $i$ and $j$, if $\varepsilon_{i}(p)>\varepsilon_{j}(p)$ and $A_{j}>A_{i}>0$ then $C_{i}^{D}(p)<C_{j}^{D}(p)$ and $C_{i}^{I}(p)<C_{j}^{I}(p)$. It is easy to find examples where $\underline{C}_{s}^{D}>\bar{C}_{w}^{D}$ and $\underline{C}_{s}^{I}>\bar{C}_{w}^{I}$ (for example, with two markets, $s$ and $w, a_{s}=a_{w}$ and $A_{s}>A_{w}>0$ ), and therefore where Theorem 1 would imply that output increases given that the sufficient condition is satisfied. When $\varepsilon_{i}(p)>\varepsilon_{j}(p)$ and $A_{i}>A_{j}>0$, we have $C_{i}^{D}(p)>C_{j}^{D}(p)$ and $C_{i}^{I}(p)>C_{j}^{I}(p)$. This case is studied by Cowan and Vickers (2007). In their analysis when $\bar{C}_{s}^{D}<\underline{C}_{w}^{D}$ and $\bar{C}_{s}^{I}<\underline{C}_{w}^{I}$ total output decreases. Note that according to Theorem 1 the necessary condition for price discrimination to increase output is not satisfied.

When demands are strictly convex, given two arbitrary markets $i$ and $j$, if $\varepsilon_{i}(p)>\varepsilon_{j}(p)$ and $0>A_{j}>A_{i}$ then $C_{i}^{D}(p)<C_{j}^{D}(p)$ and $C_{i}^{I}(p)<$ $C_{j}^{I}(p)$. Cowan and Vickers (2007) show that when $\underline{C}_{s}^{D}>\bar{C}_{w}^{D}$ and $\underline{C}_{s}^{I}>\bar{C}_{w}^{I}$, output increases. According to Theorem 1 the sufficient condition for price discrimination to increase output is satisfied. When $\varepsilon_{i}(p)>\varepsilon_{j}(p)$ and $0>$ $A_{i}>A_{j}$, we have that $C_{i}^{D}(p)>C_{j}^{D}(p)$ and $C_{i}^{I}(p)>C_{j}^{I}(p)$. It is possible to find examples where $\bar{C}_{s}^{D}<\underline{C}_{w}^{D}$ and $\bar{C}_{s}^{I}<\underline{C}_{w}^{I}$, and Theorem 1 implies that total output decreases.

\section{Concluding remarks}

The analysis of the effects of third-degree price discrimination on total output (and, therefore, on social welfare) has been the focus of much theoretical research at least from the pioneering work by Robinson (1933). In this paper, we show that in order for third-degree price discrimination to increase 
total output the demands of the strong markets should be, as conjectured by Robinson (1933), in some sense more concave than the demands of the weak markets. By making the distinction between adjusted concavity of the inverse demand and adjusted concavity of the direct demand we are able to state necessary conditions and sufficient conditions for third-degree price discrimination to increase total output. The results obtained are rather general and they seem robust to other cost structure (increasing marginal cost) or to more general comparisons of concavity.

Independently, Cowan (2008) has recently obtained sufficient conditions for third-degree price discrimination to increase or to reduce social welfare, being also crucial the relative concavity of the demand and the inverse demand of the strong markets in comparison with the weak markets. His results on welfare nicely complement our results concerning the output effect. For example, in his Proposition 2 welfare increases if the inverse demand function in the weak market is more convex at the discriminatory price than the inverse demand in the strong market and the discriminatory prices are close. But then both the direct demand and the inverse demand would be more convex in the weak market than in the strong market (the sufficient condition, in theorem 1, for third-degree price discrimination to increase total output). Therefore, given that the output increases, the social welfare will increase if the price difference is small enough that the output effect dominates the misallocation effect.

\section{References}

Aguirre, I. (2006). "Monopolistic price discrimination and output effect under conditions of constant elasticity demand". Economics Bulletin, vol. 4, No 23 pp. 1-6.

Aguirre, I. (2008). "Output and misallocation effects in monopolistic thirddegree price discrimination". Economics Bulletin, vol. 4, No 11 pp. 1-6.

Battalio, R. C., and Ekelund, R. B. (1972). "Output change under third degree discrimination". Southern Economic Journal, vol. 39, pp. 285-290.

Bertoletti, P. (2004). "A note on third-degree price discrimination and output". Journal of Industrial Economics, vol. 52, No 3, 457; available at the "Journal of Industrial Economics (JIE) Notes and Comments page", http:www.essex.ac.uk/jindec/notes.htm.

Cheung, F. K., and Wang, X. (1994). "Adjusted concavity and the output 
effect under monopolistic price discrimination". Southern Economic Journal, vol. 60, pp. 1048-1054.

Cowan, S. (2007). "The welfare effects of third degree price discrimination with non-linear demand functions". Rand Journal of Economics, vol. 38, pp. 419-428.

Cowan, S., and J. Vickers (2007). "Output and welfare effects in the classic monopoly price discrimination problem". Discussion paper $\mathrm{n}^{\circ} 355$, Department of Economics, University of Oxford.

Cowan, S. (2008). "When does third-degree price discrimination reduce social welfare, and when does it raise it?". Discussion paper $n^{\circ} 410$, Department of Economics, University of Oxford.

Edwards, E. O. (1950). "The analysis of output under discrimination". Econometrica, vol. 18, pp. 163-172.

Formby, J. P., Layson, S. K. and Smith, W. J. (1983). "Price discrimination, adjusted concavity, and output changes under conditions of constant elasticity". Economic Journal, Vol. 93, 892-899.

Hausman, J.A., and MacKie-Mason, J. K. (1988). "Price discrimination and patent policy". Rand Journal of Economics 19, 253-265.

Ippolito, R. A. (1980). "Welfare effects of price discrimination when demand curves are constant elasticity". Atlantic Economic Journal, vol. 8, pp. 89-93. Layson, S. K. (1994). "Market opening under third-degree price discrimination". Journal of Industrial Economics, vol. 42, pp. 335-340.

Leontief, W. W. (1940). "The theory of limited and unlimited discrimination". Quarterly Journal of Economics, vol. 54, pp. 490-501.

Löfgren, K. G. (1977). "A note of output under discrimination". Rivista Internacionale di Scienze Economiche, vol. 24, pp. 776-782.

Pigou, A.C. (1920). The Economics of Welfare. London: Macmillan.

Robinson, J. (1933) (1969, 2ed.). The Economics of Imperfect Competition. London: Macmillan.

Schmalensee, R. (1981). "Output and welfare implications of monopolistic third-degree price discrimination". American Economic Review, vol. 71, pp. 242-247.

Schwartz, M. (1990). "Third-degree price discrimination and output: generalizing a welfare result". American Economic Review, vol. 80, pp. 1259-1262. Shih, J., Mai, C. and Liu, J. (1988). "A general analysis of the output effect under third-degree price discrimination". Economic Journal, vol. 98, pp. 149-158. 
Silberberg, E. (1970). "Output under discrimination: a revisit". Southern Economic Journal, vol. 37, pp. 84-87.

Smith, W. J. and Formby, J. P. (1981). "Output changes under third degree price discrimination: a re-examination". Southern Economic Journal, vol. 48, pp. 164-171.

Varian, H.R. (1985). "Price discrimination and social welfare". American Economic Review, vol. 75, pp. 870-875. 